\title{
Mechanisms of exercise intolerance in Global Initiative for Chronic Obstructive Lung Disease grade 1 COPD
}

\author{
Jordan A. Guenette ${ }^{1,2,3}$, Roberto C. Chin ${ }^{1}$, Sicheng Cheng ${ }^{1}$, Paolo B. Dominelli', \\ Natya Raghavan ${ }^{1}$, Katherine A. Webb ${ }^{1}$, J. Alberto Neder ${ }^{5}$ and Denis E. O'Donnell ${ }^{1,5}$

\begin{abstract}
Affiliations: 'Respiratory Investigation Unit, Queen's University and Kingston General Hospital, Kingston, ON, Canada. ${ }^{2}$ Dept of Physical Therapy, University of British Columbia, Vancouver, BC, Canada. ${ }^{3}$ Centre for Heart Lung Innovation, Providence Health Care Research Institute, University of British Columbia, St. Paul's Hospital, Vancouver, BC, Canada. "School of Kinesiology, University of British Columbia, Vancouver, BC, Canada. ${ }^{5}$ Division of Respiratory and Critical Care Medicine, Queen's University and Kingston General Hospital, Kingston, ON, Canada.
\end{abstract}

Correspondence: Denis E. O'Donnell, Division of Respiratory and Critical Care Medicine, Queen's University, 102 Stuart Street, Kingston, ON, K7L 2V6, Canada. E-mail: odonnelldqueensu.ca

ABSTRACT The purpose of this study was to determine if a dissociation existed between respiratory drive, as estimated by diaphragmatic electromyography (EMGdi), and its pressure-generating capacity during exercise in mild chronic obstructive pulmonary disease (COPD) and whether this, if present, had negative sensory consequences.

Subjects meeting spirometric criteria for mild $\operatorname{COPD}(\mathrm{n}=16)$ and age and sex-matched controls $(\mathrm{n}=16)$ underwent detailed pulmonary function testing and a symptom limited cycle test while detailed ventilatory, sensory and respiratory mechanical responses were measured.

Compared with controls, subjects with mild COPD had greater ventilatory requirements throughout submaximal exercise. At the highest equivalent work rate of $60 \mathrm{~W}$, they had a significantly higher: total work of breathing ( $32 \pm 17$ versus $16 \pm 7 \mathrm{~J} \cdot \mathrm{min}^{-1}$; $\left.\mathrm{p}<0.01\right)$; EMGdi $(37.3 \pm 17.3$ versus $17.9 \pm 11.7 \%$ of maximum; $\mathrm{p}<0.001)$; and $\mathrm{EMGdi}$ to transdiaphragmatic pressure ratio $(0.87 \pm 0.38$ versus $0.52 \pm 0.27$; $\mathrm{p}<0.01)$. Dyspnoea-ventilation slopes were significantly higher in mild COPD than controls $(0.17 \pm 0.12$ versus $0.10 \pm 0.05 ; \mathrm{p}<0.05)$. However, absolute dyspnoea ratings reached significant levels only at high levels of ventilation.

Increased respiratory effort and work of breathing, and a wider dissociation between diaphragmatic activation and pressure-generating capacity were found at standardised work rates in subjects with mild COPD compared with controls. Despite these mechanical and neuromuscular abnormalities, significant dyspnoea was only experienced at higher work rates.

@ERSpublications

Mild COPD patients experience respiratory mechanical abnormalities during exercise despite relatively preserved FEV1 http://ow.ly/yHukJ

Received: Feb 202014 | Accepted after revision: June 142014 | First published online: Aug 192014

Support statement: This study received funding from a William Spear/Richard Start Endowment Fund, Queen's University, and the Ontario Thoracic Society. J.A. Guenette was supported by postdoctoral fellowships from the Natural Sciences and Engineering Research Council of Canada (NSERC), the Canadian Thoracic Society and the Canadian Lung Association, as well as a New Investigator Award from the Providence Health Care Research Institute and St. Paul's Hospital Foundation. R.C. Chin was supported by the Queen's Graduate Award and the Queen Elizabeth II Graduate Scholarship in Science and Technology. P.B. Dominelli was supported by an NSERC Canada Graduate Scholarship.

Conflict of interest: Disclosures can be found alongside the online version of this article at erj.ersjournals.com 


\section{Introduction}

Despite having relatively preserved spirometry, patients with milder chronic obstructive pulmonary disease (COPD) show increased mortality [1], increased hospitalisations, and decreased health-related quality of life [2-5] compared with nonsmoking controls. Many of these patients also experience exertional dyspnoea [6], which may partially explain their reduced physical activity levels [7]. Despite these findings, this subpopulation has not been extensively studied and no evidence-based recommendations currently exist for their management beyond smoking cessation. Therefore, the optimal management of patients with mild COPD awaits a better understanding of their underlying pathophysiology.

The clinical presentation of patients with mild airway obstruction is highly variable and depends on the integration of several factors such as the nature and extent of their physiological impairment, the attendant compensatory respiratory system adjustments, and complex behavioural adaptations (e.g. activity avoidance). The heterogeneous physiological abnormalities of patients with mild airway obstruction include: increased peripheral airway resistance, early airway closure, maldistribution of ventilation, impaired pulmonary gas exchange and gas trapping [8-12]. Recent studies have shown that these physiological abnormalities are amplified during exercise $[6,13,14]$. Thus, the combination of ventilatory inefficiency and abnormal ventilatory mechanics can force the respiratory system to prematurely reach its physiological limits at lower exercise intensities than in healthy controls [13].

The current study extends previous work [15-17] to determine if a dissociation exists between diaphragmatic activation and pressure generation or between respiratory muscle effort and the mechanical output of the respiratory system during exercise in patients with mild COPD and whether such factors have negative sensory consequences. Therefore, the current study tested the hypotheses that: 1) dissociation between respiratory neural drive and the muscular/mechanical response of the respiratory system would be present in mild COPD at lower work rates than in healthy controls; and 2) these compensatory adjustments to support the increased ventilatory demands of exercise would be associated with an earlier onset of intolerable dyspnoea.

\section{Methods}

\section{Subjects}

The study included 16 subjects with Global Initiative for Chronic Obstructive Lung Disease grade 1 COPD (forced expiratory volume in $1 \mathrm{~s}(\mathrm{FEV} 1$ )/forced vital capacity (FVC) $<0.70$ and FEV $1 \geqslant 80 \%$ predicted) and 16 healthy age- and sex-matched controls. Subjects were recruited through advertisements and through the respiratory clinic at Kingston General Hospital (Kingston, ON, Canada). Individuals with cardiovascular, metabolic, neuromuscular or any other disease that could contribute to dyspnoea or interfere with exercise testing were excluded.

\section{Study design}

This study received ethical approval from the Queen's University and Affiliated Hospitals Research Ethics Board (DMED-1285-10). Subjects participated in two testing visits. On visit one, a detailed medical history was completed, followed by chronic activity-related dyspnoea questionnaires, pre- and post-bronchodilator $(400 \mu \mathrm{g}$ salbutamol) pulmonary function testing and a symptom-limited incremental cycle test for familiarisation purposes. On visit two, subjects performed pulmonary function testing followed by the same exercise protocol but with additional measurements of diaphragmatic electromyography (EMGdi) and respiratory pressures. COPD subjects refrained from using their short- and long-acting bronchodilators for 6 and $24 \mathrm{~h}$ prior to testing, respectively, and avoided caffeine, heavy meals and alcohol for at least $4 \mathrm{~h}$ prior to testing.

\section{Pulmonary function}

Spirometry, body plethysmography, single-breath diffusing capacity of the lung for carbon monoxide (DLCO), single-breath nitrogen test, maximal mouth pressures and impulse oscillometry were performed using an automated testing system (Vs62j Body Plethysmograph, Vmax229d Encore and Masterscreen IOS; SensorMedics, Yorba Linda, CA) according to established guidelines and expressed as \% pred of normal values.

\section{Cardiopulmonary exercise testing}

Exercise was performed on an electronically-braked cycle ergometer (Ergometrics 800S; SensorMedics) using a cardiopulmonary testing system (Vmax229d; SensorMedics). Testing involved a rest period and a $1 \mathrm{~min}$ warm-up of unloaded pedalling followed by stepwise increases of $20 \mathrm{~W}$ per 2 min until symptom limitation. Standard cardiopulmonary measurements were collected on a breath-by-breath basis. Blood pressure, heart rate and oxyhaemoglobin saturation were monitored using sphygmomanometry, electrocardiography, and pulse oximetry, respectively. Inspiratory capacity (IC) measurements were 
performed at rest, every second minute during exercise and at the end of exercise [18]. Subjects rated the intensity of their "breathing discomfort" and "leg discomfort" at rest, every second minute during exercise and at the end of exercise using the modified 10-point Borg scale [19]. Subjects were asked to report their primary reason for stopping exercise and to select qualitative phrases that described how their breathing felt at peak exercise [20]. An inflection in tidal volume $(V \mathrm{~T})$ relative to minute ventilation $\left(V^{\prime} \mathrm{E}\right)$ was determined for each subject during exercise [21]. The highest equivalent work rate (HEWR) was defined as the highest work rate achieved by all subjects.

\section{Diaphragmatic EMG and respiratory pressures}

A combined electrode-balloon catheter was passed through the nose and positioned as previously described [22]. Raw EMGdi signals were sampled at $2000 \mathrm{~Hz}$ (PowerLab, model ML880; ADInstruments, Castle Hill, Australia), band-pass filtered between $20-1000 \mathrm{~Hz}$ (Bio-amplifier model RA-8; Guangzhou Yinghui Medical Equipment Co. Ltd, Guangzhou, China) and converted into a root mean square. The mean root mean square for each inspiration was determined by manually selecting the EMGdi signal that fell between cardiac QRS complexes. The electrode pair with the largest EMGdi amplitude was used for the analysis. Maximal EMGdi (EMGdi,max) was determined as the highest EMGdi amplitude from any IC manoeuvre $[22,23]$. The ratio between EMGdi/EMGdi,max and $V \mathrm{~T} /$ (predicted vital capacity (VCpred)) was used as an index of neuromechanical dissociation of the respiratory system.

Oesophageal and gastric balloon catheters were connected to calibrated differential pressure transducers (model DP15-34; Validyne Engineering, Northridge, CA, USA). Transdiaphragmatic pressure (Pdi) was calculated as the difference between $P_{\text {ga }}$ and Pes. Maximal $P$ di $(P$ di,max $)$ and $P$ es $(P$ es,max $)$ were determined during maximal IC and sniff manoeuvres, respectively. The work of breathing was determined as the area within an averaged tidal Pes-volume loop and was further subdivided into the inspiratory resistive and inspiratory elastic work of breathing [24]. The breath selection occurred over the same $30 \mathrm{~s}$ as all other cardiorespiratory and EMG data (i.e. the first $30 \mathrm{~s}$ of each second minute of exercise). An index of ventilatory muscle recruitment was calculated as the difference between end-inspiratory and end-expiratory $P$ ga divided by the difference between end-inspiratory and end-expiratory $P$ es $\left(\Delta P_{\text {ga }} / \Delta P\right.$ es $)[25]$.

\section{Data analysis}

Between-group comparisons of subject characteristics, and physiological and sensory variables at each time point during exercise were performed using unpaired t-tests. Qualitative descriptors of dyspnoea at peak exercise and the reasons for stopping exercise were analysed using Fisher's exact test. To evaluate the relationship between dyspnoea intensity (dependent variable) and relevant independent variables during exercise, the following were included in a multivariable linear regression model: the independent variable of interest, group as a categorical effect, an interaction term to determine whether the relationship being tested was similar across groups (independent variable $\times$ group), and subjects were treated as random effects to account for serial measurements (subject nested within group). Results are reported as mean \pm SD, unless otherwise specified. A p-value $<0.05$ was used for statistical significance.

\section{Results}

Subjects

Descriptive characteristics of the mild COPD subjects $(n=16)$ and controls $(n=16)$ are summarised in table 1 . Subjects with mild COPD had a significant smoking history (range 15-111 pack-years) including 12 exsmokers and four current smokers. Only two control subjects had a smoking history of 2.5 and 2 pack-years each, while all other controls were never-smokers. Nine COPD subjects used respiratory medications on a regular basis: short-acting $\beta_{2}$-agonist as needed $(n=7)$, short-acting anticholinergic $(n=2)$, long-acting anticholinergic $(n=5)$, inhaled corticosteroid $(n=1)$, and a long-acting $\beta_{2}$-agonist combined with an inhaled corticosteroid $(n=6)$. Comorbidities in the COPD group included the following: hypertension $(n=10)$, diabetes mellitus type $2(n=4)$, hypercholesterolaemia $(n=3)$, osteoarthritis $(n=3)$, anxiety $(n=2)$, gastrooesophageal reflux $(n=1)$, and sleep apnoea $(n=1)$. Comorbidities in the healthy control group included the following: hypertension $(n=3)$, osteoarthritis $(n=3)$, hypercholesterolaemia $(n=1)$, sleep apnoea $(n=1)$, and anaemia $(n=1)$. None of the COPD subjects had participated in pulmonary rehabilitation.

All but one COPD subject was below the lower limit of normal for FEV1/FVC [26]. Compared with controls, subjects with mild COPD had significantly greater activity-related dyspnoea, airway resistance, $\mathrm{N}_{2}$ slope, resonant frequency, functional residual capacity, residual volume, and a greater difference between total lung capacity and alveolar volume. They also had a significantly reduced IC, DLCO and static respiratory muscle strength. 
TABLE 1 Subject characteristics

Controls

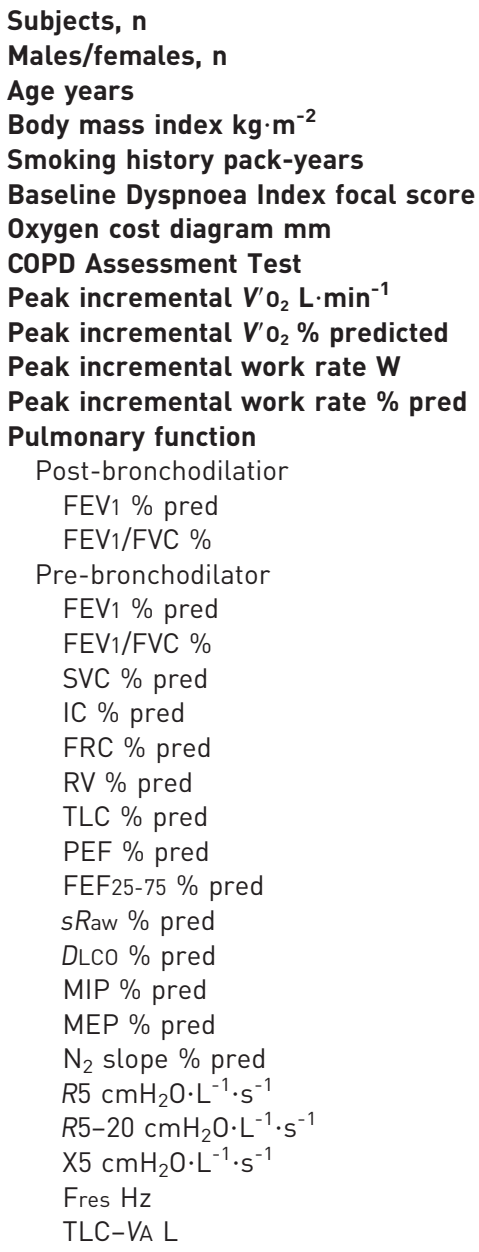

Mild COPD

$\begin{array}{cc}16 & 16 \\ 8 / 8 & 8 / 8 \\ 63 \pm 9 & 67 \pm 7 \\ 27.5 \pm 2.5 & 26.8 \pm 6.1 \\ 0.3 \pm 0.8 & 46.9 \pm 28.8^{* * *} \\ 11.3 \pm 0.9 & 9.1 \pm 2.2^{* *} \\ 89 \pm 11 & 74 \pm 14^{* *} \\ 4 \pm 4 & 13 \pm 8^{* * *} \\ 2.55 \pm 0.88 & 1.61 \pm 0.48^{* * *} \\ 114 \pm 27 & 80 \pm 14^{* * *} \\ 178 \pm 62 & 102 \pm 30^{* * *} \\ 116 \pm 21 & 76 \pm 20^{* * *} \\ & \\ 120 \pm 12 & \\ 77 \pm 5 & 93 \pm 9 * * * \\ & 63 \pm 4^{* * *} \\ 116 \pm 13 & \\ 74 \pm 6 & 86 \pm 9^{* * *} \\ 116 \pm 13 & 59 \pm 5^{* * *} \\ 116 \pm 17 & 105 \pm 11^{*} \\ 89 \pm 21 & 99 \pm 19^{*} \\ 81 \pm 20 & 109 \pm 19^{* *} \\ 102 \pm 14 & 110 \pm 23^{* * *} \\ 120 \pm 19 & 104 \pm 9 \\ 91 \pm 34 & 92 \pm 16^{* * *} \\ 132 \pm 57 & 33 \pm 10^{* * *} \\ 102 \pm 15 & 245 \pm 104^{* * *} \\ 113 \pm 25 & 82 \pm 21^{* *} \\ 89 \pm 20 & 87 \pm 37^{*} \\ 206 \pm 69 & 70 \pm 18^{* *} \\ 4.36 \pm 1.16 & 416 \pm 230^{* *} \\ 12.5 \pm 7.3 & 5.22 \pm 1.74 \\ -1.12 \pm 0.54 & 22.7 \pm 9.8^{* *} \\ 12.1 \pm 3.5 & -1.77 \pm 0.86^{*} \\ 0.63 \pm 0.41 & 16.2 \pm 4.7^{*} \\ & 1.15 \pm 0.32^{* * *}\end{array}$

Data are presented as mean $\pm S D$, unless otherwise stated. COPD: chronic obstructive pulmonary disease; $V^{\prime} \mathrm{O}_{2}$ : oxygen uptake; $\mathrm{FEV}$ : forced expiratory volume in $1 \mathrm{~s}$; FVC: forced vital capacity; SVC: slow vital capacity; IC: inspiratory capacity; FRC: functional residual capacity; RV: residual volume; TLC: total lung capacity; PEF: peak expiratory flow; FEF25-75: force expiratory flow at 25-75\% of FVC; sRaw: specific airway resistance; DLCO: diffusing capacity of the lung for carbon monoxide; MIP: maximal inspiratory pressure; MEP: maximal expiratory pressure; $\mathrm{N}_{2}$ : nitrogen; R5: resistance at $5 \mathrm{~Hz}$; R5-20: difference in resistance between $5 \mathrm{~Hz}$ and $20 \mathrm{~Hz}$; X5: distal capacitive reactance at $5 \mathrm{~Hz}$; Fres: resonant frequency during impulse oscillometry; VA: alveolar volume. ${ }^{*}: \mathrm{p}<0.05{ }^{* *}: \mathrm{p}<0.01 ;^{* * *}: \mathrm{p}<0.001$.

\section{Physiological responses to exercise}

Peak work rate and oxygen uptake $\left(V^{\prime} \mathrm{O}_{2}\right)$ were significantly lower in subjects with mild COPD compared with controls. Selected sensory and physiological parameters at rest, the HEWR, and peak exercise are shown in table 2. Figure 1 shows the metabolic and ventilatory responses to exercise. Compared with controls, subjects with mild COPD had greater ventilatory inefficiency (fig. 1b), higher ventilatory requirements (fig. 1c), and higher operating lung volumes during exercise (fig. 1f). A discernible $V \mathrm{~T} / V^{\prime} \mathrm{E}$ inflection occurred in all subjects except for one subject with mild COPD. The $V \mathrm{~T} / V^{\prime} \mathrm{E}$ inflection (denoted as triangles in the figure) occurred at a significantly lower $V^{\prime} \mathrm{O}_{2}, V^{\prime} \mathrm{E}$ and work rate in the subjects with mild COPD compared with controls. 
TABLE 2 Selected sensory and physiological parameters at rest, the HEWR, and peak exercise

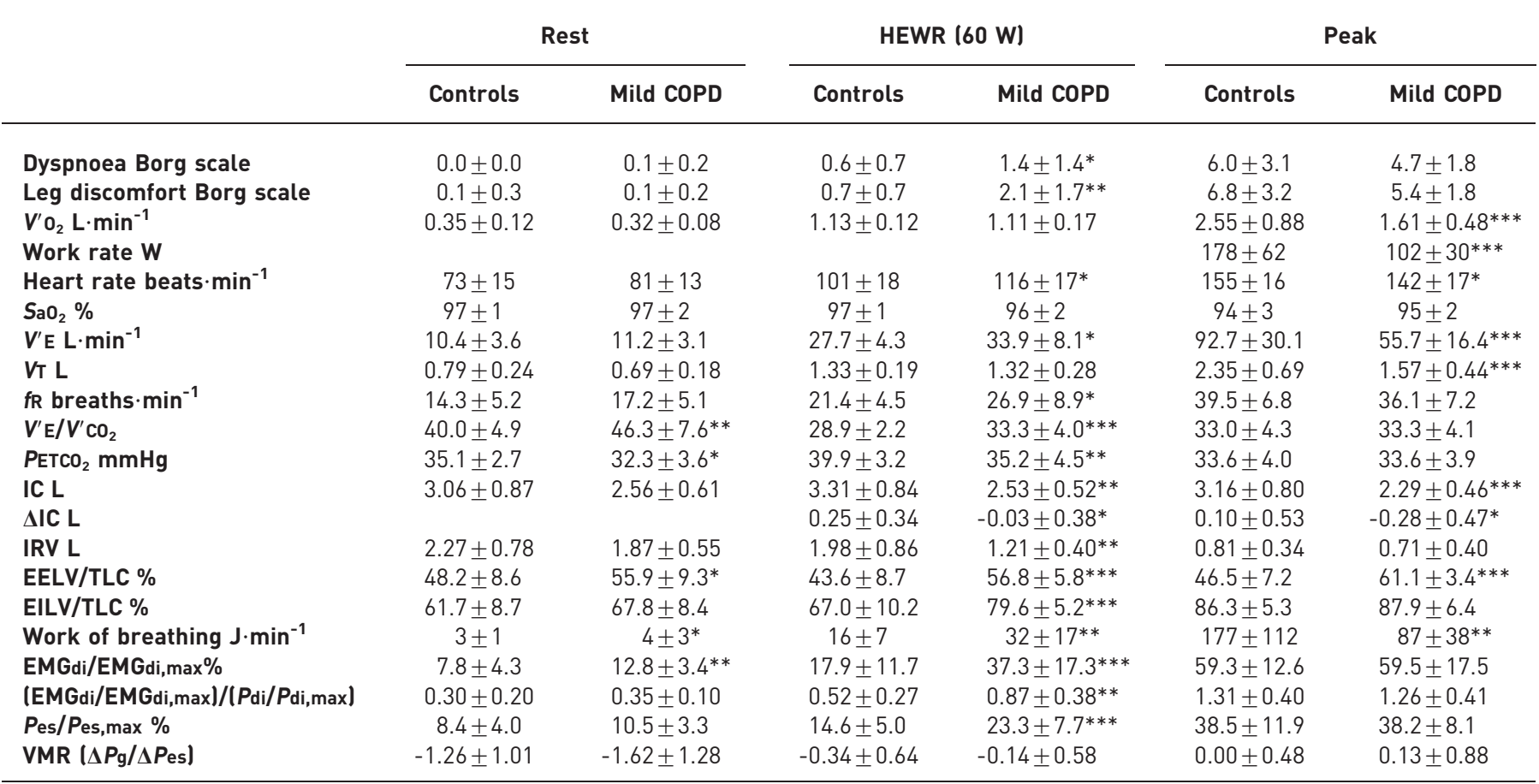

Data are presented as mean \pm SD. HEWR: highest equivalent work rate; COPD: chronic obstructive pulmonary disease; $V^{\prime} \mathrm{O}_{2}$ : oxygen uptake; $\mathrm{SaO}_{2}$ : arterial oxygen saturation; $V^{\prime} \mathrm{E}$ : minute ventilation; $V_{T}$ : tidal volume; fR: respiratory frequency; $V^{\prime} \mathrm{CO}_{2}$ : carbon dioxide production; $P$ ETCO ${ }_{2}$ : end-tidal carbon dioxide tension; IC: inspiratory capacity; $\triangle \mathrm{IC}$ : change in IC from rest; IRV: inspiratory reserve volume; EELV: end-expiratory lung volume; TLC: total lung capacity; EILV: end-inspiratory lung volume; EMGdi: diaphragmatic electromyography; EMGdi,max: maximal EMGdi; Pdi: transdiaphragmatic pressure; Pdi,max: maximal Pdi; Pes: tidal oesophageal pressure; Pes,max: maximal Pes; VMR: ventilatory muscle recruitment; $\Delta P$ g: change in gastric pressure. ${ }^{*}: \mathrm{p}<0.05 ;{ }^{* *}: \mathrm{p}<0.01 ;{ }^{* *}: \mathrm{p}<0.001$.

Respiratory mechanics and diaphragmatic function

The total work of breathing and the inspiratory elastic and resistive work of breathing were significantly elevated in mild COPD throughout submaximal exercise compared with controls (fig. 2). At the HEWR, the total work of breathing was two-fold higher in mild COPD versus controls. Peak exercise work of breathing was higher in the controls reflecting their higher peak $V^{\prime}$ E. EMGdi and mean Pdi were higher in mild COPD at rest and throughout submaximal exercise (fig. $2 \mathrm{~d}$ and $2 \mathrm{e}$, respectively). The ratio between EMGdi/EMGdi,max and $P$ di/Pdi,max was also significantly higher during exercise in subjects with mild COPD (fig. 2f). Subjects with mild COPD had lower $V$ T and $V^{\prime}$ E, and a modestly higher Pdi for any given EMGdi (fig. $3 \mathrm{a}-\mathrm{c}$ ). Total respiratory effort $(P \mathrm{es} / P \mathrm{es}$ max) was similar between groups for any given EMGdi (fig. $3 \mathrm{~d}$ ). Neuromechanical dissociation of the respiratory system, whether expressed as (EMGdi/EMGdi,max)/(VT/ VCpred) or (Pes/Pes,max)/(VT/VCpred), was significantly higher in mild COPD for any given work rate (fig. 4) or $V^{\prime} \mathrm{E}$ compared with the controls.

\section{Sensory responses to exercise}

Breathing discomfort, alone or in combination with leg discomfort was selected as the primary reason for stopping exercise in $69 \%$ of subjects with mild COPD versus $25 \%$ of healthy controls $(p=0.07)$. Leg discomfort alone was the primary reason for stopping exercise in 19\% of subjects with COPD versus $69 \%$ of healthy controls $(\mathrm{p}<0.05)$. Other reasons for stopping exercise in mild COPD included "general fatigue" $(n=2)$. One healthy control subject stopped due to a "dry mouth and throat". Phrases alluding to "inspiratory difficulty" were selected more frequently in subjects with mild COPD versus controls at peak exercise $(69 \%$ versus $25 \%$ of subjects, $\mathrm{p}<0.05)$. Dyspnoea $-V^{\prime} \mathrm{E}$ slopes were significantly higher in subjects with mild COPD versus controls $(0.17 \pm 0.12$ versus $0.10 \pm 0.05 ; \mathrm{p}<0.05)$. Dyspnoea intensity ratings were also significantly higher in mild COPD subjects at the HEWR (fig. 5a). Despite this, absolute dyspnoea ratings in the mild COPD group remained relatively low up to the $V \mathrm{~T} / V^{\prime} \mathrm{E}$ inflection, corresponding to a $V^{\prime} \mathrm{E}$ of $40.8 \pm 13.2 \mathrm{~L} \cdot \mathrm{min}^{-1}$. Dyspnoea increased similarly in both groups as a function of increasing EMGdi throughout exercise (fig. 5b). Dyspnoea intensity during exercise correlated best with $V^{\prime} \mathrm{E}$ (\% of maximum 

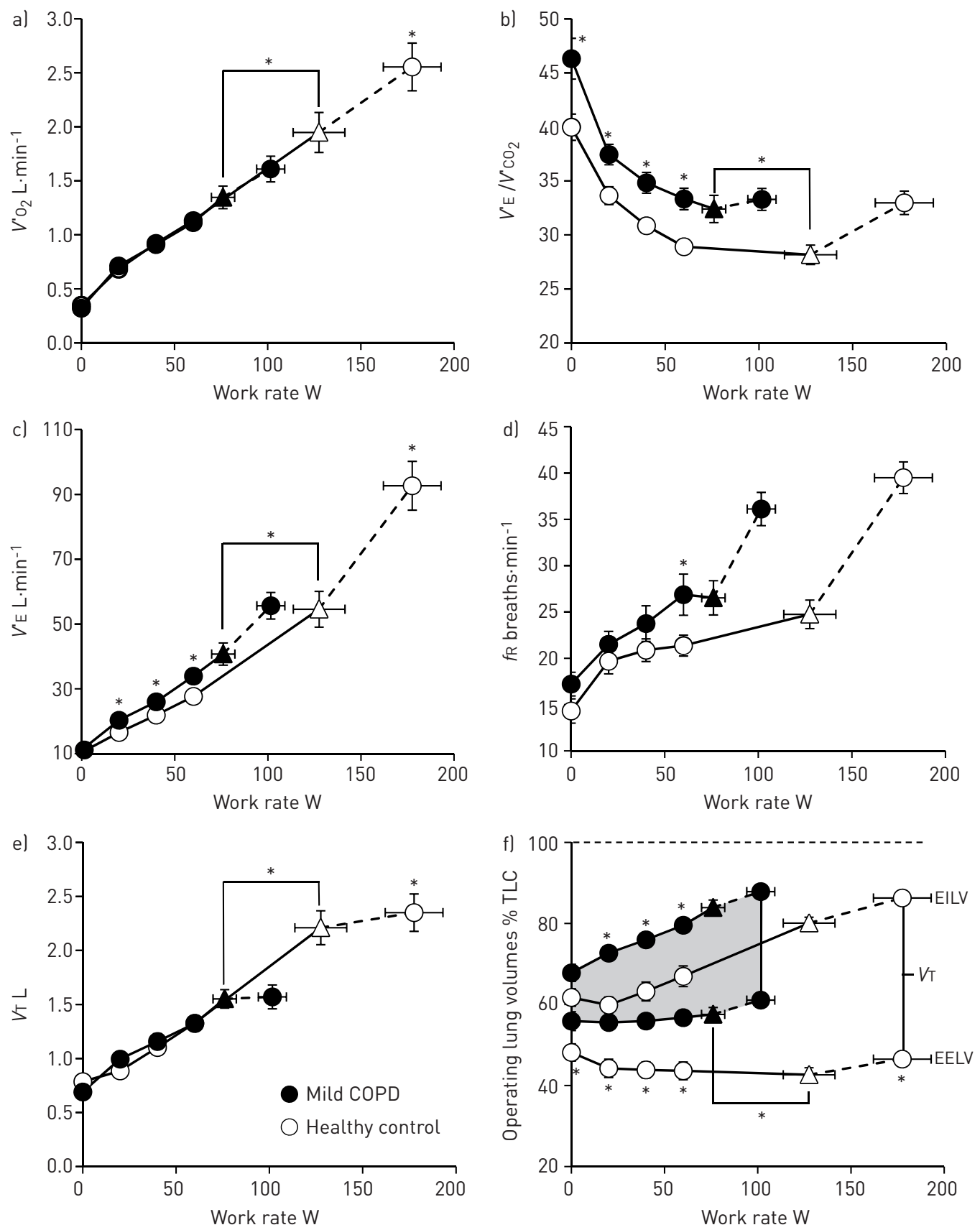

FIGURE 1 Metabolic and ventilatory responses to exercise. a) Oxygen uptake ( $\left.V^{\prime} \mathrm{O} 2\right)$, b) minute ventilation $\left(V^{\prime} \mathrm{E}\right) /$ carbon dioxide production $\left.\left.\left(V^{\prime} \mathrm{CO}_{2}\right), \mathrm{c}\right) V^{\prime} \mathrm{E}, \mathrm{d}\right)$ respiratory frequency $\left.(\mathrm{fR}), \mathrm{e}\right)$ tidal volume $(V \mathrm{~T})$ and $\mathrm{f}$ ) operating lung volumes at different work rates. COPD: chronic obstructive pulmonary disease; TLC: total lung capacity; EILV: end-inspiratory lung volume; EELV: end-expiratory lung volume. Data are presented as mean $\pm \mathrm{SEM}$. Triangles represent the $V \mathrm{~T} / V^{\prime} \mathrm{E}$ inflection. ${ }^{*}: \mathrm{p}<0.05$.

voluntary ventilation), Pes/Pes,max and EMGdi/EMGdi,max (all $\mathrm{p}<0.0005)$; these relationships were similar across groups. Indices of neuromechanical dissociation (i.e. Pes/VT and EMG/VT ratios) were more weakly associated with dyspnoea, but these relationships showed a significant $(\mathrm{p}<0.005)$ group interaction.

\section{Discussion}

The novel findings of this study are as follows. 1) The resistive and elastic loads on the respiratory muscles were significantly increased resulting in increased diaphragmatic activation, respiratory effort and work of breathing in mild COPD relative to controls at standardised work rates. 2) In COPD, there was a widening 

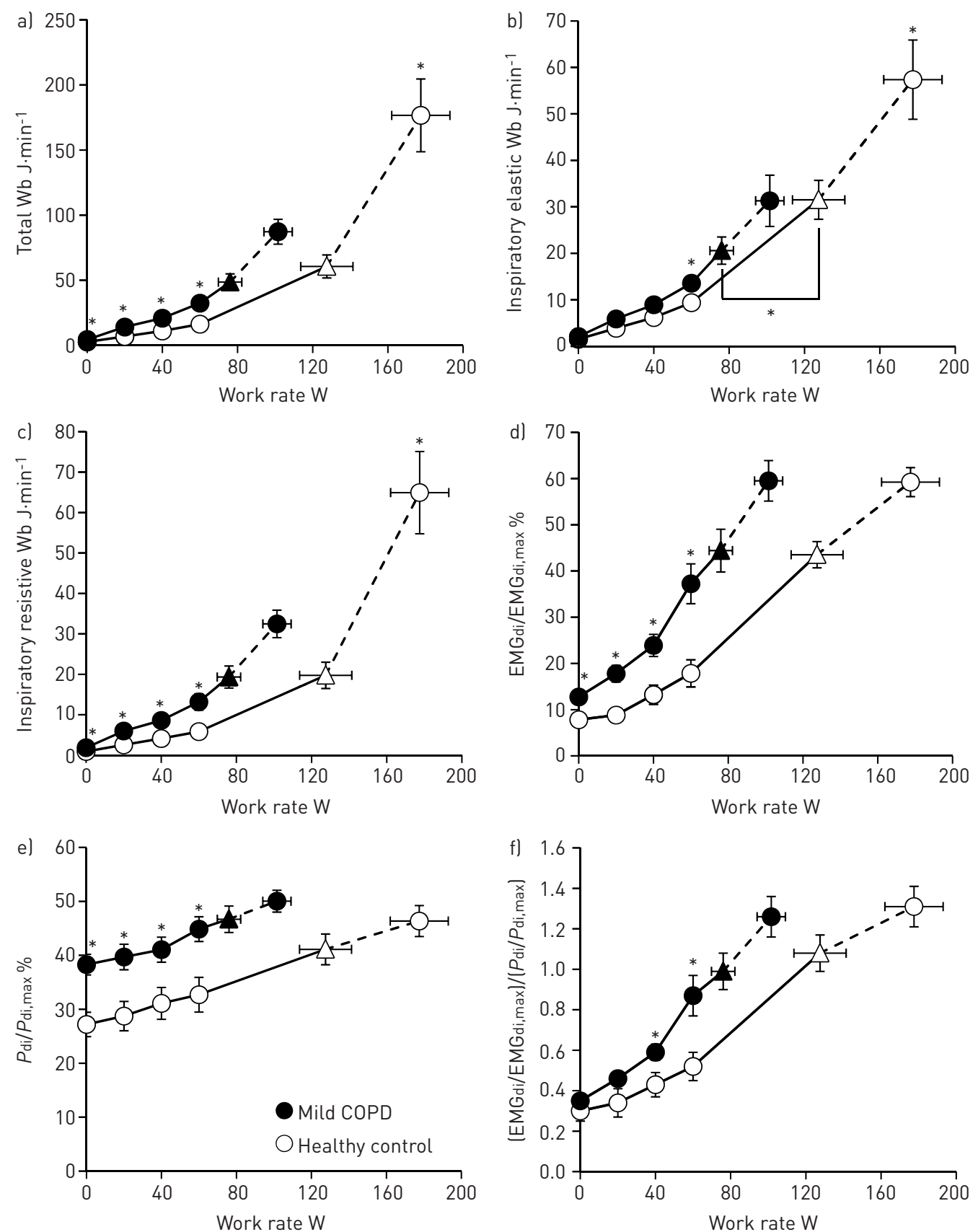

FIGURE 2 Work of breathing and diaphragmatic function in response to exercise. a) Total work of breathing (Wb), b) inspiratory elastic $\mathrm{Wb}, \mathrm{c}$ ) inspiratory resistive $\mathrm{Wb}, \mathrm{d}$ ) ratio of diaphragmatic electromyography (EMGdi) to maximal EMGdi (EMGdi,max), e) ratio of transdiaphragmatic pressure (Pdi) to maximal Pdi (Pdi,max) and f) ratio of EMGdi/ EMGdi,max to $P \mathrm{di} / P \mathrm{di}$, max at different work rates. Data are presented as mean \pm sEM. Triangles represent the tidal volume/ minute ventilation inflection. COPD: chronic obstructive pulmonary disease. ${ }^{*}: \mathrm{p}<0.05$.

dissociation between indices of respiratory neural drive and the muscular and mechanical response of the respiratory system at lower work rates compared with controls. 3) Despite the mechanical and neuromuscular adaptations needed to support increased ventilation, subjects with mild COPD did not experience significant dyspnoea during moderate submaximal work rates.

Although the mild COPD group had only minor spirometric abnormalities and minimal lung hyperinflation at rest, they had evidence of significant peripheral airway dysfunction as indicated by a reduction in mid-volume maximal expiratory flows, maldistribution of ventilation, pulmonary gas trapping and negative frequency dependence of resistance. These subjects also had mild-to-moderate activity-related 

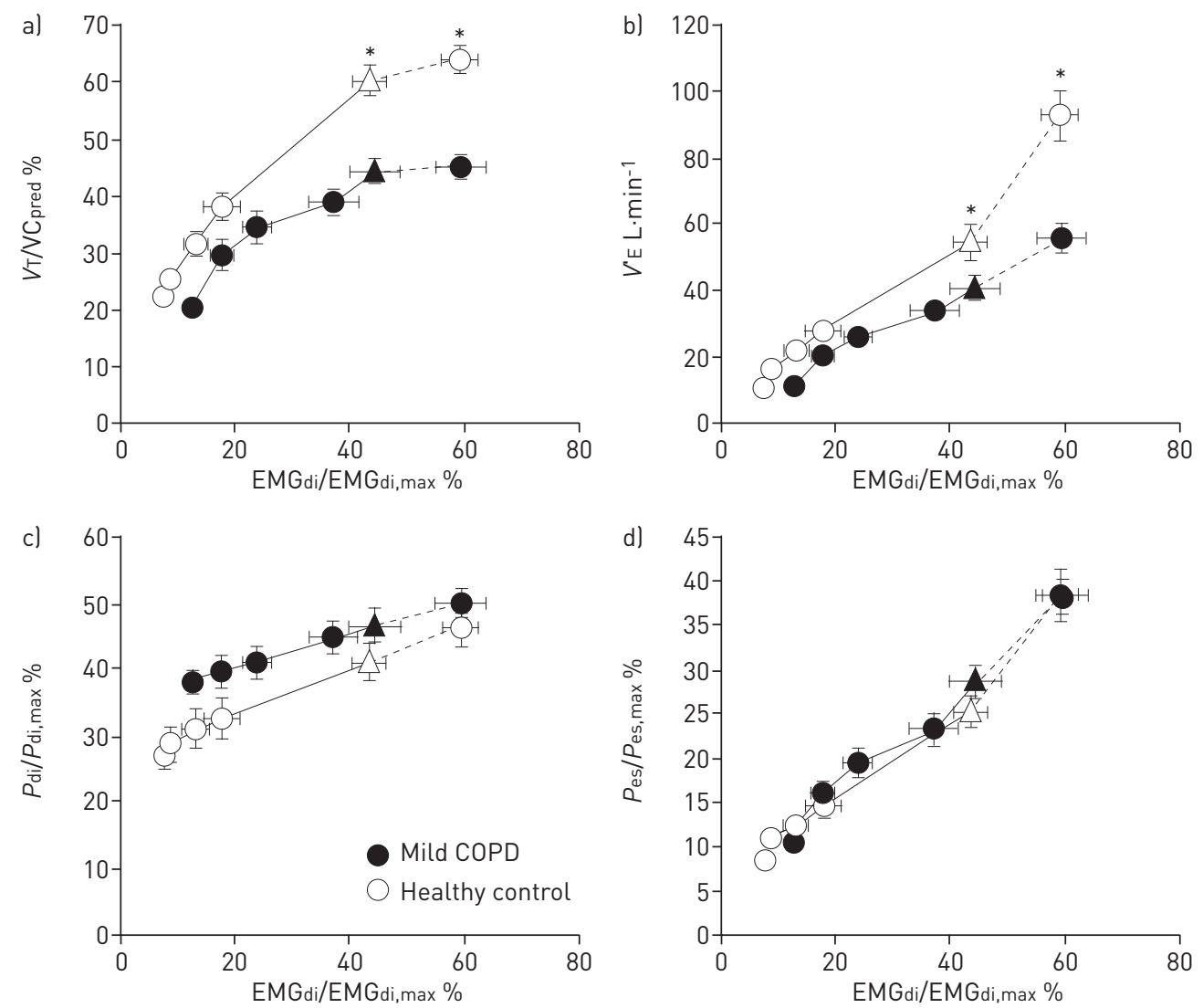

FIGURE 3 Ventilatory and respiratory pressure responses for a given level of diaphragmatic activation. a) Ratio of tidal volume $(V \mathrm{~T})$ to predicted vital capacity (VCpred), b) minute ventilation $\left(V^{\prime} \mathrm{E}\right)$, c) ratio of transdiaphragmatic pressure $(P \mathrm{di})$ to maximal $P$ di $(P$ di, $\max )$ and d) ratio of tidal oesophageal pressure $(P$ es $)$ to maximal $P$ es $(P$ es, max $)$ at different diaphragmatic electromyography (EMGdi) to maximal EMGdi (EMGdi,max) ratios. Data are presented as mean \pm SEM. Triangles represent the $V \mathrm{~T} / V^{\prime} \mathrm{E}$ inflection. Statistical comparisons were performed at the $V_{\mathrm{T}} / V^{\prime} \mathrm{E}$ inflection and at peak exercise. COPD: chronic obstructive pulmonary disease. ${ }^{\star}: \mathrm{p}<0.05$.

dyspnoea and moderately impaired health status. Absolute peak work rate and $V^{\prime} \mathrm{O}_{2}$ were significantly lower in the COPD group relative to controls and predicted values. Collectively, these results demonstrate that subjects with mild airway obstruction can have important physiological and clinical abnormalities despite having relatively preserved spirometry.

Our results confirm previous reports of significant ventilatory abnormalities in subjects with mild COPD during exercise (fig. 1) $[6,14,27]$. For example, greater ventilatory inefficiency (high $V^{\prime} \mathrm{E} /$ carbon dioxide production $\left.\left(V^{\prime} \mathrm{CO}_{2}\right)\right)$ was present at rest and during exercise in mild COPD, likely reflecting an increased physiological dead space due to regional increases in ventilation/perfusion ratios. Our mild COPD group also had evidence of dynamic hyperinflation at peak exercise $(\sim 0.3 \mathrm{~L})$, along with greater tachypnoea and an earlier $V_{\mathrm{T}}$ inflection, indicating that the end-inspiratory lung volume encroached on total lung capacity (TLC) (88\% of TLC) at a lower work rate $(102$ versus $178 \mathrm{~W})$ and $V^{\prime} \mathrm{E}\left(55.7\right.$ versus $\left.92.7 \mathrm{~L} \cdot \mathrm{min}^{-1}\right)$ than in the controls.

Compared with controls, subjects with mild COPD had greater resistive and elastic loading of the inspiratory muscles resulting in an increased total work of breathing for any given submaximal work rate. At the HEWR, the total work of breathing was two-fold greater in mild COPD relative to controls and this was predominantly driven by a higher inspiratory resistive work of breathing. Respiratory muscle effort was also markedly higher in mild COPD subjects across all submaximal work rates. Thus, to perform the same standardised physical task, subjects with mild COPD consistently had greater erosion of their respiratory reserve than healthy individuals.

\section{Diaphragmatic function and dynamic respiratory mechanics}

To our knowledge, this is the first study to examine detailed measures of diaphragmatic function in individuals with mild airway obstruction. EMGdi was markedly higher in this group at rest and throughout all submaximal work rates. The ratio of EMGdi to Pdi was also significantly higher relative to controls, 

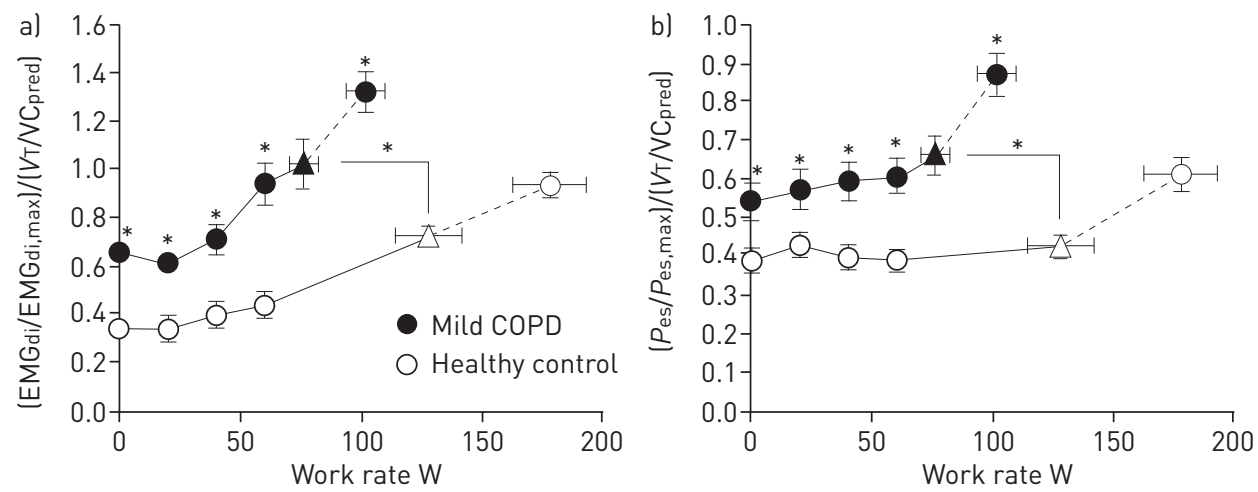

FIGURE 4 Neuromechanical dissociation of the respiratory system. As exercise progresses there is an increasing disparity between a) the ratio of diaphragmatic electromyography (EMGdi) to maximal EMGdi (EMGdi,max) or b) the ratio of tidal oesophageal pressure $\left(P_{\mathrm{es}}\right)$ to maximal $P_{\mathrm{es}}\left(P_{\mathrm{es}, \mathrm{max}}\right)$ and the tidal volume $(V \mathrm{~T})$ response in mild chronic obstructive pulmonary disease (COPD) compared with healthy controls. VCpred: predicted vital capacity. Data are presented as mean \pm SEM. Triangles represent the $V \mathrm{~T} / V^{\prime} \mathrm{E}$ inflection. ${ }^{*}: \mathrm{p}<0.05$.

indicating some degree of neuromuscular dissociation of the diaphragm. This higher ratio was driven, in part, by the more rapid increase in EMGdi since the rate of increase in Pdi was similar in both groups and increased linearly with increasing exercise intensity (fig. 2e). This is in contrast with the work by SINDERBY et al. [17] in moderate-to-severe COPD, where a plateau in Pdi occurred relatively early during exercise despite a continued increase in EMGdi. The authors proposed that this was the result of reduced pressure generating capacity of the diaphragm due to lung hyperinflation. Patients with moderate-to-severe COPD have been shown to have an EMGdi of $70 \%$ of maximum at peak incremental exercise corresponding to a $V^{\prime} \mathrm{E}$ of $32.3 \pm 9.6 \mathrm{~L} \cdot \mathrm{min}^{-1}$ using the same catheter as used in the present study [28]. At a similar absolute $V^{\prime} \mathrm{E}$ $\left(33.9 \pm 8.1 \mathrm{~L} \cdot \mathrm{min}^{-1}\right)$, we found that patients with mild COPD have an EMGdi of $37 \%$ of maximum, suggesting that respiratory neural drive increases dramatically with advancing COPD severity. Accordingly, the relatively preserved pressure generating capacity of the diaphragm in our mild COPD subjects probably reflects the presence of less severe mechanical constraints. In keeping with this, the pattern of ventilatory muscle recruitment during exercise was not different in mild COPD and controls. Nevertheless, the higher diaphragmatic activation and EMGdi to Pdi ratio in mild COPD indicates the presence of important compensatory physiological adaptations. Specifically, the combination of increased mechanical loading and pulmonary gas exchange abnormalities led to an increase in neural activation of the diaphragm and total respiratory muscle contractile effort, which permitted subjects to achieve the alveolar ventilation required to meet the metabolic demands of moderate physical work.

It has long been understood that there is a widening disparity between the drive to breathe and the corresponding mechanical output of the impaired respiratory system during exercise in advanced COPD [29]. Since respiratory neural drive cannot be measured directly, we rely on indirect estimates such as
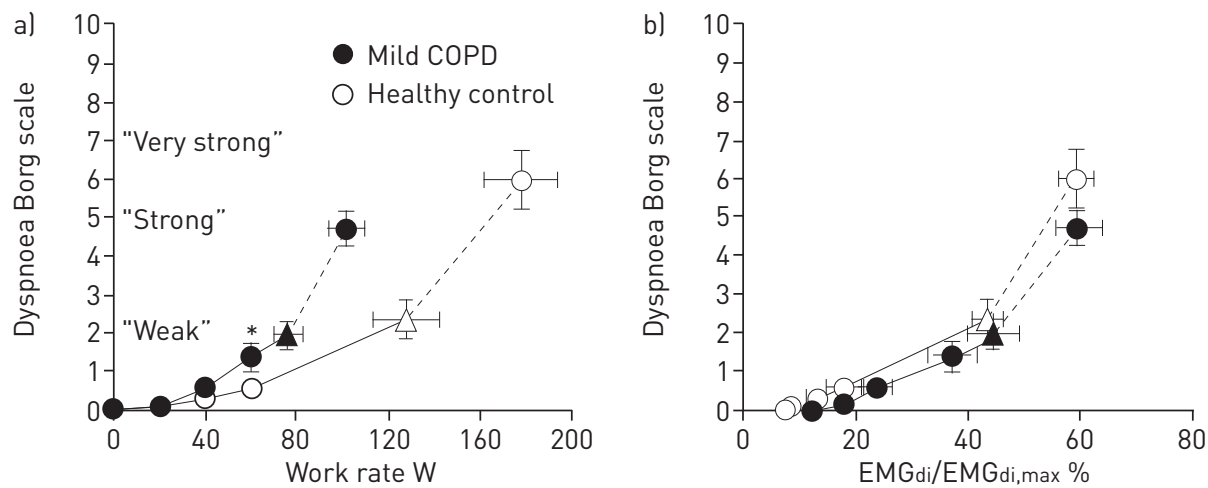

FIGURE 5 Dyspnoea intensity in response to exercise. Dyspnoea measured using the modified 10-point Borg scale in response to exercise measured as a) work rate and b) the ratio of diaphragmatic electromyography (EMGdi) to maximal EMGdi (EMGdi,max). Data are presented as mean \pm SEM. Triangles represent the tidal volume/minute ventilation inflection. COPD: chronic obstructive pulmonary disease. *: $\mathrm{p}<0.05$. 
measures of effort (i.e. Pes/Pes,max). Unfortunately, this approach can lead to significant underestimation in the setting of severe respiratory mechanical impairment $[17,30,31]$. The additional use of EMGdi as a surrogate for respiratory neural drive in mild COPD [32] is unique to this study. Increases in EMGdi/ EMGdi,max and Pes/Pes,max were closely correlated (fig. 3d) throughout exercise in health and mild COPD, thus supporting the contention that these measures are reasonable surrogates of respiratory neural drive, at least in this population. Remarkably, even in the setting of mild spirometric abnormality, $V \mathrm{~T}$ expansion and, thus, $V^{\prime}$ E was significantly reduced for a given EMGdi (and respiratory muscle effort) compared with controls (fig. $3 \mathrm{a}$ and $3 \mathrm{~b}$ ). This inability to appropriately expand $V \mathrm{~T}$ is probably explained by the prevailing mechanical ventilatory constraints. This latter contention is bolstered by the previous finding that bronchodilators, by decreasing lung hyperinflation, allow greater $V \mathrm{~T}$ expansion during exercise in mild COPD $[33,34]$.

\section{Dyspnoea}

Despite the compensatory increases in diaphragmatic activation and respiratory effort needed to maintain $V^{\prime} \mathrm{E}$ in pace with increasing metabolic demands, minimal dyspnoea was experienced up to $80 \mathrm{~W}$ or a $V^{\prime} \mathrm{E}$ of $\sim 40 \mathrm{~L} \cdot \mathrm{min}^{-1}$. The $V^{\prime} \mathrm{O}_{2}$ at this work rate in mild COPD corresponds to approximately five metabolic equivalents. Thus, by extrapolation, such patients are likely to be able to undertake many daily activities requiring moderate exertion without experiencing significant respiratory discomfort [35]. However, it is clear that more sustained or strenuous tasks would evoke severe dyspnoea. In both groups, dyspnoea increased as a function of increasing EMGdi, Pes and $V^{\prime} \mathrm{E}$, all relative to maximum. Thus, the higher dyspnoea intensity at equivalent work rates in mild COPD compared with controls, generally reflects their higher drive to breathe and respiratory muscle effort requirements. We speculate that this increasing dissociation between neural drive and the muscular/mechanical response of the respiratory system might explain the more frequent selection of the qualitative descriptor inspiratory difficulty at a much lower peak work rate in mild COPD compared with controls [16].

\section{Limitations}

This study had a small sample size due to the complexity and invasiveness of the EMGdi and respiratory pressure measurements. Despite this, our sample size was sufficient to detect significant differences in dyspnoea intensity and a wide range of physiological and respiratory mechanical outcome variables of interest. The mild COPD subjects who participated in this study had, on average, mild-to-moderate activity-related dyspnoea. Thus, our results may not be generalisable to asymptomatic subjects with mild COPD [36].

\section{Conclusions and implications}

In patients with a relatively preserved $\mathrm{FEV}_{1}$, extensive mechanical and respiratory neuromuscular adaptations were already in place, which allowed them to adequately meet the metabolic demands of moderate physical activity. However, maximal exercise capacity was diminished in these patients, and our study is the first to show that this was associated with the inability of the respiratory system to appropriately increase ventilation in the face of increasing diaphragmatic activation and contractile respiratory muscle effort. These compensatory adjustments in mild COPD appeared to have little negative influence on respiratory sensation until higher levels of ventilation were required to support increased exercise intensities. These results highlight that exclusive reliance on spirometry, to assess severity of airway obstruction in patients with mild COPD, may result in underestimation of clinically important physiological impairment.

\section{References}

Mannino DM, Buist AS, Petty TL, et al. Lung function and mortality in the United States: data from the First National Health and Nutrition Examination Survey follow up study. Thorax 2003; 58: 388-393.

2 Maleki-Yazdi MR, Lewczuk CK, Haddon JM, et al. Early detection and impaired quality of life in COPD GOLD stage 0: a pilot study. COPD 2007; 4: 313-320.

3 Antonelli-Incalzi R, Imperiale C, Bellia V, et al. Do GOLD stages of COPD severity really correspond to differences in health status? Eur Respir J 2003; 22: 444-449.

4 Ferrer M, Alonso J, Morera J, et al. Chronic obstructive pulmonary disease stage and health-related quality of life. The Quality of Life of Chronic Obstructive Pulmonary Disease Study Group. Ann Intern Med 1997; 127: 1072-1079. Jones PW. Health status measurement in chronic obstructive pulmonary disease. Thorax 2001; 56: 880-887.

Ofir D, Laveneziana P, Webb KA, et al. Mechanisms of dyspnea during cycle exercise in symptomatic patients with GOLD stage I chronic obstructive pulmonary disease. Am J Respir Crit Care Med 2008; 177: 622-629.

7 Van Remoortel H, Hornikx M, Demeyer H, et al. Daily physical activity in subjects with newly diagnosed COPD. Thorax 2013; 68: 962-963.

8 Buist AS, Ross BB. Quantitative analysis of the alveolar plateau in the diagnosis of early airway obstruction. Am Rev Respir Dis 1973; 108: 1078-1087. 
9 Deesomchok A, Webb KA, Forkert L, et al. Lung hyperinflation and its reversibility in patients with airway obstruction of varying severity. COPD 2010; 7: 428-437.

10 Rodríguez-Roisin R, Drakulovic M, Rodríguez DA, et al. Ventilation-perfusion imbalance and chronic obstructive pulmonary disease staging severity. J Appl Physiol 2009; 106: 1902-1908.

11 Barberà JA, Riverola A, Roca J, et al. Pulmonary vascular abnormalities and ventilation-perfusion relationships in mild chronic obstructive pulmonary disease. Am J Respir Crit Care Med 1994; 149: 423-429.

12 Barbera JA, Ramirez J, Roca J, et al. Lung structure and gas exchange in mild chronic obstructive pulmonary disease. Am Rev Respir Dis 1990; 141: 895-901.

13 Chin RC, Guenette JA, Cheng S, et al. Does the respiratory system limit exercise in mild chronic obstructive pulmonary disease? Am J Respir Crit Care Med 2013; 187: 1315-1323.

14 Guenette JA, Jensen D, Webb KA, et al. Sex differences in exertional dyspnea in patients with mild COPD: physiological mechanisms. Respir Physiol Neurobiol 2011; 177: 218-227.

15 O'Donnell DE, Hamilton AL, Webb KA. Sensory-mechanical relationships during high-intensity, constant-workrate exercise in COPD. J Appl Physiol 2006; 101: 1025-1035.

16 O'Donnell DE, Ora J, Webb KA, et al. Mechanisms of activity-related dyspnea in pulmonary diseases. Respir Physiol Neurobiol 2009; 167: 116-132.

17 Sinderby C, Spahija J, Beck J, et al. Diaphragm activation during exercise in chronic obstructive pulmonary disease. Am J Respir Crit Care Med 2001; 163: 1637-1641.

18 Guenette JA, Chin RC, Cory JM, et al. Inspiratory capacity during exercise: measurement, analysis, and interpretation. Pulm Med 2013; 2013: 956081.

19 Borg GA. Psychophysical bases of perceived exertion. Med Sci Sports Exerc 1982; 14: 377-381.

20 Simon PM, Schwartzstein RM, Weiss JW, et al. Distinguishable types of dyspnea in patients with shortness of breath. Am Rev Respir Dis 1990; 142: 1009-1014.

21 Hey EN, Lloyd BB, Cunningham DJ, et al. Effects of various respiratory stimuli on the depth and frequency of breathing in man. Respir Physiol 1966; 1: 193-205.

22 Jensen D, O'Donnell DE, Li R, et al. Effects of dead space loading on neuro-muscular and neuro-ventilatory coupling of the respiratory system during exercise in healthy adults: implications for dyspnea and exercise tolerance. Respir Physiol Neurobiol 2011; 179: 219-226.

23 Sinderby C, Beck J, Spahija J, et al. Voluntary activation of the human diaphragm in health and disease. J App Physiol 1998; 85: 2146-2158.

24 Dominelli PB, Sheel AW. Experimental approaches to the study of the mechanics of breathing during exercise. Respir Physiol Neurobiol 2012; 180: 147-161.

25 Martinez FJ, Couser JI, Celli BR. Factors influencing ventilatory muscle recruitment in patients with chronic airflow obstruction. Am Rev Respir Dis 1990; 142: 276-282.

26 Hankinson JL, Odencrantz JR, Fedan KB. Spirometric reference values from a sample of the general U.S. population. Am J Respir Crit Care Med 1999; 159: 179-187.

27 Chin R, Guenette JA, Cheng J, et al. A comparison of the mechanical and sensory consequences of dead space loading during exercise in mild COPD and in health. Am J Respir Crit Care Med 2012; 185: A1547.

28 Luo YM, Li RF, Jolley C, et al. Neural respiratory drive in patients with COPD during exercise tests. Respiration 2011; 81: 294-301.

29 O'Donnell DE, Banzett RB, Carrieri-Kohlman V, et al. Pathophysiology of dyspnea in chronic obstructive pulmonary disease: a roundtable. Proc Am Thorac Soc 2007; 4: 145-168.

30 Hussain SN, Pardy RL, Dempsey JA. Mechanical impedance as determinant of inspiratory neural drive during exercise in humans. J Appl Physiol 1985; 59: 365-375.

31 Mendonca CT, Schaeffer MR, Riley P, et al. Physiological mechanisms of dyspnea during exercise with external thoracic restriction: role of increased neural respiratory drive. J Appl Physiol 2014; 116: 570-581.

32 Luo YM, Moxham J. Measurement of neural respiratory drive in patients with COPD. Respir Physiol Neurobiol 2005; 146: 165-174.

33 O'Donnell DE, Laveneziana P, Ora J, et al. Evaluation of acute bronchodilator reversibility in patients with symptoms of GOLD stage I COPD. Thorax 2009; 64: 216-223.

34 Guenette JA, Webb KA, O'Donnell DE. Effect of fluticasone/salmeterol combination on dyspnea and respiratory mechanics in mild-to-moderate COPD. Respir Med 2013; 107: 708-716.

35 Ainsworth BE, Haskell WL, Whitt MC, et al. Compendium of physical activities: an update of activity codes and MET intensities. Med Sci Sports Exerc 2000; 32: Suppl., S498-S504.

36 Díaz AA, Morales A, Díaz JC, et al. CT and physiologic determinants of dyspnea and exercise capacity during the six-minute walk test in mild COPD. Respir Med 2013; 107: 570-579. 